\title{
Traumatic Atlanto-occipital Dislocation (AOD)
}

\author{
Yeon-Joon Kim, Chan-Jong Yoo, Chan-Woo Park, \\ Sang-Gu Lee, Seong Son, Woo-Kyung Kim \\ Department of Neurosurgery, Gachon University Gil Hospital, Incheon, Korea
}

\begin{abstract}
Objective: Traumatic atlanto-occipital dislocation (AOD) results from high energy trauma and is an uncommon and usually fatal injury due to an injury to the cervicomedullary junction. Recently, improved prehospital management, early diagnosis and effective treatment led to increasing reports of survival. This study of patients with AOD initial imaging modalities recognizes the clinical features and diagnostic considerations for a quick diagnosis.

Methods: In this article, five survived adult patients with traumatic AOD are presented and retrospectively reviewed. Diagnosis was made by lateral cervical spine $\mathrm{x}$-ray, cervical computed tomography (CT), or magnetic resonance imaging(MRI). Treatment consisted of early immobilization, respiratory support, and subsequent occipitocervical fusion.

Results: Four patients were male and the other one was female. Three were diagnosed early and the others were delayed in confirmations. One was type I AOD and four were type II AOD. All patients were applied occipitocervical fusion. Two cases were worse; neurological states and the other three that showed no change. Lateral X-ray film of all patients in the prevertebral soft tissue swelling at the C2 level was noted. The mean thickness of prevertebral soft tissue C2 level was 17.88 $\mathrm{mm}$ (15.18 to $20.17 \mathrm{~mm}$ ). Two were in the normal range of dens-basion index(DBI), three showed abnormalities, and Power's ratio was abnormal in 3 patients.

Conclusion: As for damages caused by a strong external force in patients with severe prevertebral soft tissue swelling at C2 level abnormaly, the doctor determines whether more should be carefully AOD and considers 3D CT or MRI to confirm $A O D$ in these patients.
\end{abstract}

Key Words: Atlanto-occipital dislocation • Occipito-cervical fixation $\cdot$ Craniovertebral junction · Atlanto-occipital joint $\cdot$ Occipital condyle

\section{INTRODUCTION}

Traumatic atlanto-occipital dislocation (AOD) results from severe a ligamentous injury, which usually has either a fatal or a potentially devastating outcome ${ }^{21)}$. Patients frequently succumb to a cervicomedullary injury from $\mathrm{AOD}$ at the site of the accident. In previous autopsy studies, traumatic AOD accounted for $6-8 \%$ of all traffic fatalities and are related to $20 \%$ to 30 $\%$ of patients whose deaths are directly related to cervical spine injuries ${ }^{1,3,8)}$.

Continued improvement in the emergency management of this lesion with its better recognition, however, has resulted in more adult patients arriving at trauma centers in a viable

- Received: February 9, 2012 • Revised: June 21, 2012

- Accepted: June 22, 2012

Corresponding author: Chan-Jong Yoo, M.D.

Address: Department of Neurosurgery, Gachon University Gil Hospital,

1198 Block, Guwol-dong, Namdong-gu, Incheon 405-760, Korea

Tel: 82-32-460-3304, Fax: 82-32-460-3899

E-mail: nschan@gilhospital.com state ${ }^{18,21,27}$. Improvement of diagnostic tools and effective treatment lead to increasing reports of survival ${ }^{2,6,10,12,19,21,23,27,30,31)}$.

The radiological diagnosis of AOD can made using lateral cervical spine plain films, computerized tomographic (CT) scans with sagittal and coronal reconstructions, and/or magnetic resonance imaging (MRI), with the latter often showing concomitant ligamentous injury ${ }^{9}$. A high index of suspicion for AOD and Prompt recognition of it along with cervical immobilization of a patient with this injury are essential in order to promote survival.

The purpose of this study was to identify the clinical features and imaging modalities of five patients with post-traumatic AOD survivors.

\section{MATERIAL AND METHODS}

Patients treated with traumatic AOD were included for a study. All patients were reviewed on electrical medical records with regarding age, sex, cause of injury, physical examination, radiological results, clinical course, and outcome. Patients un- 
derwent external immobilization immediately when diagnosed with AOD. Subsequently, the patients underwent operation when their general conditions were stabilized. An operation was performed under general anesthesia with a prone position. A manual reduction was attempted while a head was fixated. Occipito-cervical fusion was performed with posterior approach. Halo-vest or rigid cervical orthosis was applied after the operation.

\section{RESULTS}

Four patients were male and the other one was female. The mean age was 34.6 year old (range, 24-50). Three were in car traffic accidents, one a motorcycle accident and the other one a pedestrian traffic accident. Three were diagnosed early and the others were delayed in confirmation. Type I AOD was one and type II AOD was 4. All patients were applied occipitocervical fusion. Two cases were worse; neurological states and the other three that showed no change. In an initial imaging study, lateral X-ray film of all patients in the prevertebral soft tissue swelling at the $\mathrm{C} 2$ level was noted. The mean thickness of prevertebral soft tissue C2 level was $17.9 \mathrm{~mm}(15.2$ to $20.2 \mathrm{~mm}$ ). While demonstrating initial sagittal CT reconstruction, two patients were in the normal range of DBI, three showed abnormalities, and Power's ratio was abnormal in 3 patients (Table 1).

\section{Case 1}

A 26-year-old man was brought to the emergency room after a motorcycle accident. He complained of a severe pain at the neck and base of the skull and in the right upper extremity. He was alert and oriented and was intact on a neurological examination. The initial lateral cervical spine radiographs showed prevertebral soft tissue swelling (width: $20 \mathrm{~mm}$ ), a left $\mathrm{C} 1$ ring fracture, and widening of the gap between the odontoid and basion (Fig. 1A). A CT scan of the head and cer- vical spine (Fig. 1B, 1C, 1D) demonstrated approximately 13 $\mathrm{mm}$ of atlanto-occipital dissociation with a left medially displaced Type III occipital condyle fracture and a left $\mathrm{C} 1$ ring fracture. There was anterior displacement and separation of the occipital condyle, as well. The basion-dens interval was 14.71 $\mathrm{mm}$ (normal value, $<10 \mathrm{~mm}$ ) and the Power's ratio was 1.21 (normal value, <1.0). He was diagnosed with a Type I AOD. The preoperative MRI showed the disruption of the tectorial membrane and anterior and posterior longitudinal ligaments (Fig. 1E). The CT angiogram was suggestive for an arterial dissection. Formal angiography was negative. Additionally, plain films identified a Galeazzi fracture of the right upper extremity.

In the operating room, fluoroscopy confirmed continued atlanto-occipital dissociation. Attempts to manually reduce the separation by the way of head positioning were only partially successful. Thus, a posterior midline approach was used to expose the occiput to $\mathrm{C} 3$. $\mathrm{C} 1$ and $\mathrm{C} 2$ screws were independently placed into the $\mathrm{C} 1$ lateral mass and $\mathrm{C} 2$ pedicles ${ }^{18)}$. A DePuy Mountaineer occipital plate of the appropriate size was secured to the occipital bone using midline anchor screws. Prebent titanium rods were shaped, so as to reduce the deformity and to reapproximate the bony surfaces placed, and secured to the screws and plate. The exposed bone was decorticated carefully and an arthrodesis was accomplished with autograft and allograft. Routine wound closure was performed. Halo immobilization was not used, whereas only a rigid cervical orthosis was applied after surgery. 18 months after surgery, no neurological deficits were present and flexion and extension films of the cervical spine showed excellent alignment and instrumentation (Fig. 1F).

\section{Case 2}

A 40-year-old man was involved in a rollover motor vehicular accident and sustained polytrauma. His injuries included a left scapular comminuted fracture, multiple rib fractures, pulmonary contusions, a left hemothorax, pelvic bone fractures, and a proximal descending aortic. His initial Glasgow

Table 1. Prevertebral soft tissue swelling: soft tissue thickness $>4 \mathrm{~mm}$ at C2 level on lateral radiography DBI: Dens-Basion Index

\begin{tabular}{lclcccccc}
\hline \hline & Age & Sex & $\begin{array}{c}\text { Prevertebral soft tissue } \\
\text { swelling }\end{array}$ & DBI & Power's Ratio & AOD Type & $\begin{array}{c}\text { Time of } \\
\text { diagnosis }\end{array}$ & $\begin{array}{c}\text { Neurology } \\
\text { change }\end{array}$ \\
\hline Case 1 & 26 & Male & $+(20.0 \mathrm{~mm})$ & 14.71 & 1.21 & I & early & No change \\
Case 2 & 40 & Female & $+(17.9 \mathrm{~mm})$ & 15.41 & 1.054 & $\|$ & delayed & Worse \\
Case 3 & 33 & Male & $+(15.2 \mathrm{~mm})$ & 21.93 & 1.00 & $\|$ & early & No change \\
Case 4 & 50 & Female & $+(16.2 \mathrm{~mm})$ & 6.81 & 0.79 & $\|$ & early & No change \\
Case 5 & 24 & Male & $+(20.2 \mathrm{~mm})$ & 9.17 & 0.84 & $\|$ & delayed & Worse \\
\hline
\end{tabular}



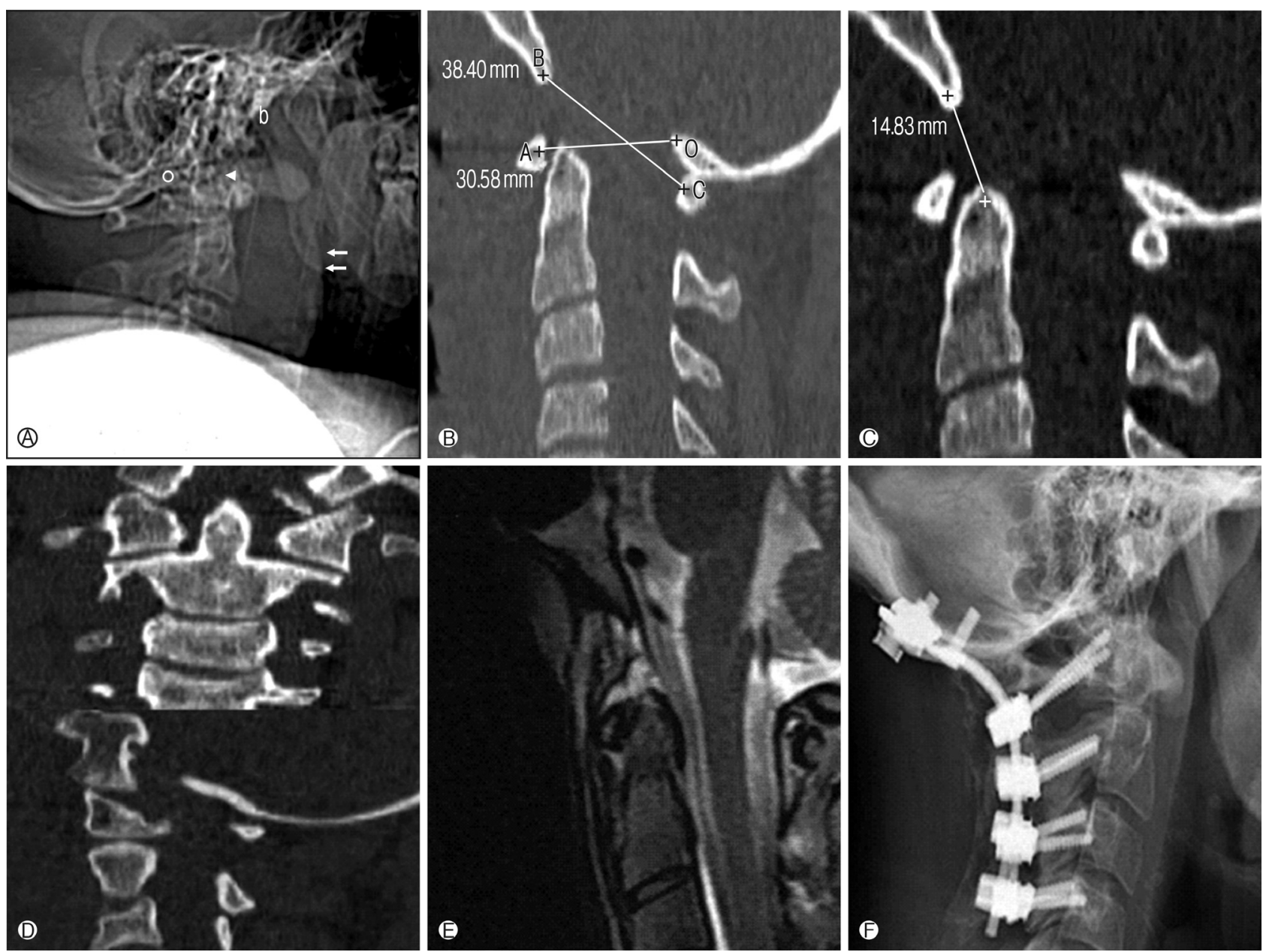

Fig. 1. A 26-yr-old man sustained an atlanto-occipital dislocation: (A) The initial lateral radiography suggested swelling of the prevertebral soft tissue and a widened gap between odontoid which is the arrowhead and basion (b). Technique and rotation limit visibility of basion (b) and opisthion (o). (B, C) Initial sagittal CT reconstruction demonstrated Power's ratio (1.21) and a basion-dens interval $(4.71 \mathrm{~mm})$. (D) The initial coronal CT reconstruction demonstrated dislocation of the right atlanto-occipital joint and a left occipital condyle fracture. (E) The preoperative sagittal MRI. (F) A plain film, 18 months after the operation shows the good stabilization and reduction of the $A O D$, and posterior bony fusion.

Coma Scale was 15. An initial head and cervical spine CT was negative for intracranial or spinal pathology. Three days after the accident, he was transferred from an outside hospital for a stent graft procedure for the aortic injury. A few days after stenting, he developed a pulmonary embolism which led to anticoagulation. He was awake and moving all four extremities to command at this time. Two weeks after the accident, he became acutely quadriplegic. A head CT demonstrated a hyperdense lesion at the anterior foramen magnum compressing the brainstem. A cervical spine MRI scan showed an acute intra- and extradural hematoma in the region of the foramen magnum causing a mass effect on the medulla (Fig. 2A). The ligament between the tip of the dens and the base of the skull was edematous and discontinuous, consistent with a rupture of this ligament. In a preoperative CT of the head and cervical spine (Fig. 2B, 2C), the basion-dens interval was $15.41 \mathrm{~mm}$. The Power's ratio was 1.054 without a fracture. There was vertical displacement of the occiput and atlas. He was diagnosed with Type II AOD. It was thought that the AOD resulted in the epi- and subdural hematomas, brain stem compression and quadriparesis. He was taken to the operating room emergently for decompression and stabilization using the same technique of direct internal occipito-atlanto-axial fixation with placement of occipital, $\mathrm{C} 1$ lateral mass, and $\mathrm{C} 2$ pedicle screws as described in the previous case with additional lateral mass instrumentation at $\mathrm{C} 3$.

This patient was then placed in a halo vest for only 2 months. Thirteen months after surgery, he was painless and is now neu- 

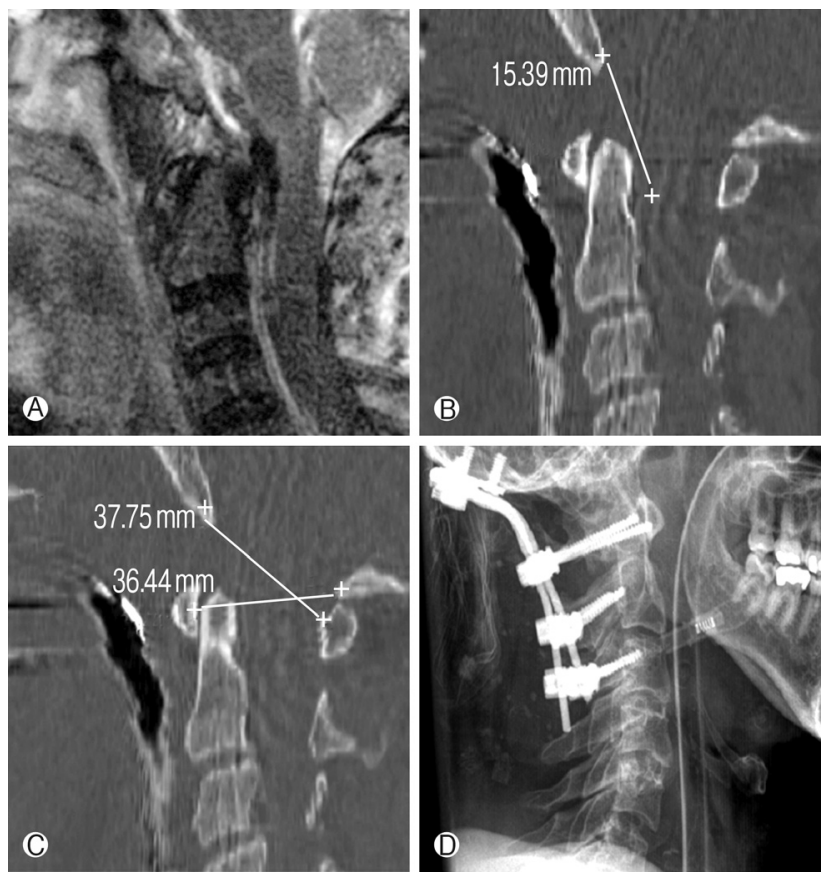

Fig. 2. Figure 2. A 40-yr old man was found to have an atlantooccipital dissociation: (A) The cervical MRI demonstrated the intraand extradural hematoma. (B, C) Preoperative sagittal CT reconstruction demonstrated basion-dens interval of $15.41 \mathrm{~mm}$ and Power's ratio of 1.054. (D) A plain film, 13 months after the operation, shows the stable anatomic alignment, was maintained, and there was good integration of the grafts.

rologically intact. Lateral cervical spine radiography showed atlanto-occipital (AO) fusion with good bony growth (Fig. 2D).

\section{Case 3}

A 32-year-old man was injured in a pedestrian-motor vehicle collision. He was found with a drowsy mentality and a neurological deficit of right side hemiparesis at the accident scene. Blood pressure was 140/80 $\mathrm{mmHg}$ and respiration was weak. Babinski sign was observed both lower extremities. The initial lateral radiography of the cervical spine suggested swelling of the prevertebral soft tissue(width: $15.18 \mathrm{~mm}$ ). Initial sagittal CT reconstruction demonstrating Power's ratio-line segments BC/OA was 38.13/37.98 mm. The resultant Power's ratio was 1.00 , and a basion-dens interval $21.93 \mathrm{~mm}$. The initial three-dimensional CT reconstruction demonstrated distraction with separation of occiput from atlas. The preoperative sagittal T2-weighted MRI showed a compressed spinal cord at the junction site of occipital condyle and atlas. He was diagnosed with Type II AOD. This patient was then placed in a halo vest for cervical stabilization. Fifteen days after trauma, the patient's general condition improved and underwent an operation. In the operating room, fluoroscopy confirmed continued atlanto-occipital dissociation. Attempts to manually reduce the separation were partially successful. Thus, a posterior midline approach was used to expose the occiput to C3. C1and $\mathrm{C} 2$ screws were independently placed into the $\mathrm{C} 1$ lateral mass and C2 pedicles. A DePuy Mountaineer occipital plate of the appropriate size was secured to the occipital bone using midline anchor screws. Prebent titanium rods were shaped, so as to reduce the deformity and to reapproximate the bony surfaces placed, and secured to the screws and plate. Halo immobilization was not used, whereas only a rigid cervical orthosis was applied after surgery. Two weeks after the accident, posterior occiput-alas-axis fixation was performed. The surgical technique was thought to be safe to perform and resulted in immediate stability. Solid fusion was achieved 5 months after surgery. He recovered progressively over a period of 6 months. Twelve months after surgery, no neurological deficit was present except for slightly right sided hemiparesis (Fig. 3).

\section{DISCUSSION}

The $\mathrm{AO}$ joint has little intrinsic bony stability, thus $\mathrm{AO}$ joint ligaments provide most of the stability of the $\mathrm{CVJ}^{22)}$. These ligaments include the anterior and posterior longitudinal (tectorial), the cruciate (transverse), and the odontoid complex (apical and alar) ligaments. Although the exact mechanism of injury remains controversial, a major disruption of the capsules and membranes at the $\mathrm{AO}$ joint with associated damage to the tectorial membrane and/or odontoid ligaments leads to severe $\mathrm{AO}$ instability in an anterior, longitudinal, or posterior direction. In several autopsy studies, traumatic AOD accounted for approximately six to eight percent of all traffic fatali$\operatorname{ties}^{28)}$. Due to improved pre-hospital care, a high index of clinical suspicion, and early recognition with better imaging techniques, the number of patients surviving AOD and arriving alive at the hospital is increasing.

The clinical presentation of patients with traumatic AOD varies and includes a wide spectrum ranging from the patient being neurologically intact to having severe neurologic deficits with ventilatory dependence and, finally, most commonly, to suffering death. Accompanying brainstem injuries and lesions involving the vascular structures of the neck contribute to the high mortality rate. The clinician should be alert to findings indicative of a brainstem injury, including respiratory insufficiency, cardiac arrhythmia, and arterial hypotension. Severe neck pain may be the only manifestation of this injury in patients who are neurologically intact.

The radiographic diagnosis is usually apparent on the initial lateral cervical radiograph, which shows prevertebral soft-tis- 

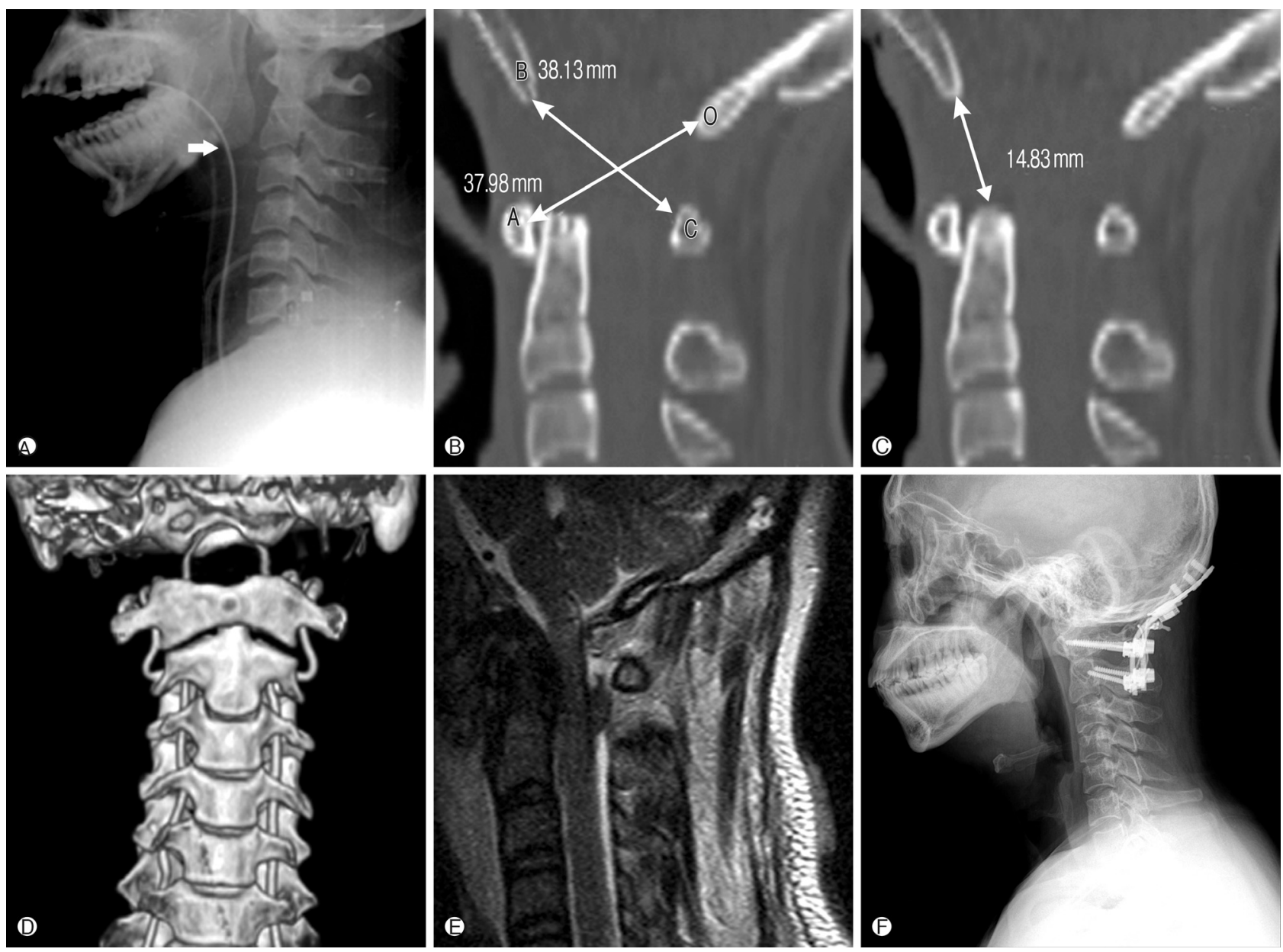

Fig. 3. A 33-yr-old man sustained an atlanto-occipital dislocation: (A) The initial lateral radiography suggested swelling of the prevertebral soft tissue. (B, C) Initial sagittal CT reconstruction demonstrated Power's ratio (1.00) and a basion-dens interval (21.93 mm). (D) The initial three-dimensional CT reconstruction demonstrated distraction with separation of occiput from atlas. (E) The preoperative sagittal T2-weighted MRI shows a compressed spinal cord at the junction site of occipital condyle and atlas. (F) A plain film, 32 months after the operation shows the good stabilization and reduction of the AOD, and posterior bony fusion.

sue swelling and displacement at the $\mathrm{CV}^{8)}$. This finding is easily missed at the initial emergency setting due to a diversity of clinical presentation, a lack of clinical suspicion, association with traumatic brain injury and polytrauma and the presence of minor subluxations ${ }^{24)}$. Once suspected, advanced imaging techniques, including CT and MRI scans are mandatory to confirm associated fractures and dislocation and to delineate the extent of ligamentous disruption and spinal cord injury ${ }^{4,5}$.

Traumatic AOD can occur as a result of several different mechanisms and can be classified according to the direction of occipital displacement (Fig. 4). Type I injuries are most common and have an anterior occipital displacement. Type II injuries have a vertical displacement $>2 \mathrm{~mm}$ be ween the occiput and C1. Type III injuries are rare and have posterior occipital displacement ${ }^{22,32)}$.

Anderson and Montesano classified occipital condyle frac- tures into three types: Type I, comminuted fractures; Type II, fractures associated with a basilar or skull fracture; and Type III, avulsion fractures. Type III, such as in case 1, occurs in 30 to $50 \%$ of patients with AOD and is generally considered unstable ${ }^{4,32)}$.

The goals of management of AOD are the reduction and stabilization of the injured segments, the preservation of neurological function, and provision of long-term $\mathrm{AO}$ stability. The initial management is directed toward maintaining adequate ventilation and cardiovascular support and includes airway protection and cervical immobilization. This can be achieved through closed reduction and immobilization with a cervical orthosis or a halo vest, but great care must be taken when manipulating the neck to avoid further neurological injury, ${ }^{4,5}$.

The surgical treatment of AOD recently underwent occipito-cervical fusion. In the occipital stabilization techniques, 

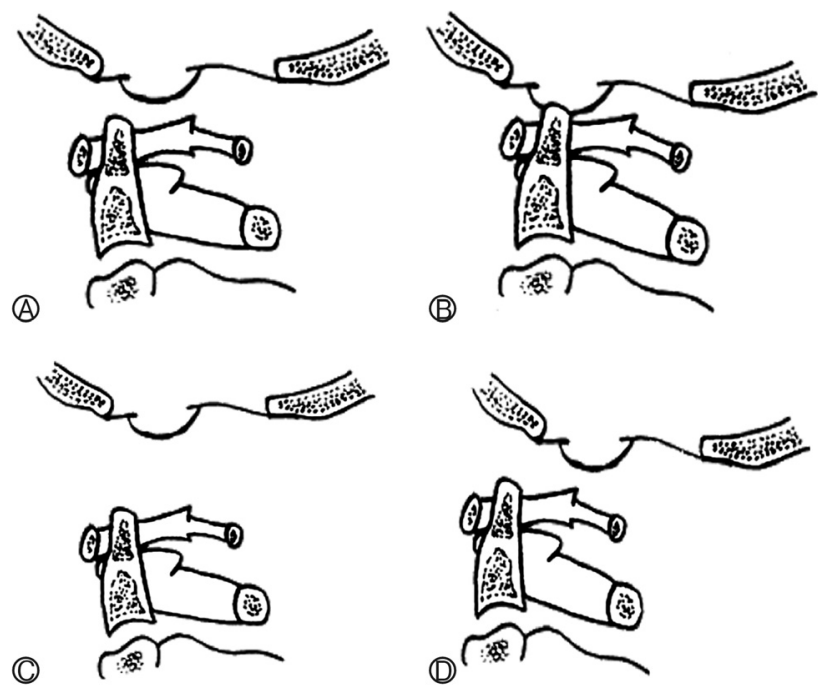

Fig. 4. Classification of atlanto-occipital dislocation (AOD) in the midsagittal representation. (A) Normal, (B) Type I: anterior dislocation, (C) Type II: vertical dislocation and (D) Type III: posterior dislocation.

Zipnick et $\mathrm{al}^{33)}$. found that the occipital bone thickness decreased radically from the occipital protuberance; the results of the pullout strength correlate with this a radically decreasing trend. The bone superior to the superior nuchal line is thicker than the corresponding area of bone below. Haher et $\mathrm{al}^{16}$. reported bicortical screw fixation gave greater overall pullout strength than did a unicortical screw in biomechanical studies. Therefore, we recommend that an occipital screw be placed near the midline crests to obtain maximal pull-out strength resistance and a bicortical occipital screw purchase by which to achieve a better stability even though this carries with it a higher risk of cerebellar and venous sinus injury.

Many techniques of dorsal atlantoaxial (AA) fixation have been developed during the past decades, all with strengths and weaknesses. Galli's dorsal wiring techniques and, Galli's fusion and Brooks's fusions are used ${ }^{7,13)}$. These methods are technically simple and require no special intraoperative equipment, but have lower rates of successful fusion and require rigid postoperative immobilization ${ }^{25)}$. To increase fusion rates and stability, Sonntag's modified Gallie fusion was developed ${ }^{11)}$. This technique, also requires a rigid postoperative external immobilization for successful fusion. Because of the limitations of rotation observed with all dorsal wiring techniques, newer techniques of dorsal AA fixation have used rigid screw fixation of the atlas and axis. Therefore, transarticular C1-C2 and $\mathrm{C} 1$ lamina and, $\mathrm{C} 2$ pedicle screw techniques provide higher fusion rates and allow for less-rigid postoperative immobilization but are technically more demanding ${ }^{25)}$.

To gain sufficient stability of the AOD, the number of cer- vical vertebrae to be incorporated into the fusion can be reduced with screw fixation. A posterior fusion extending from the occiput to at least $\mathrm{C} 2$ due to a weak posterior AA membrane is usually recommended. Grob reported a case in which a direct transarticular occipital-C1 screw fixation technique combined with an additional transarticular C1-C2 screw fixation linked to a Y-plate was successfully perfomed as a salvage procedure to treat a failed OC fusion initially performed with a rod-wire construct ${ }^{14)}$. The authors reported excellent results, with a fusion rate of $99.4 \%$ and no vertebral artery injuries ${ }^{17)}$. This technique has the advantage of a double articular fixation. Longer screws, however, are required and are used near the vertebral artery at C1 and C2 and the lower cranial nerves around the occipital condyle. By the use of lateral mass screws at $\mathrm{C} 1$ and pedicle screws at $\mathrm{C} 2$, the bony fusion is as solid as that in the transarticular screw technique, relieving the need of extending the fusion further inferiorly. The latter technique is also potentially safer than C1-C2 transarticular screws, which can injure the vertebral artery because of individual anatomical variations.

We have reviewed 5 patients with traumatic AOD. Three patients who diagnosed and treated immediately showed no neurologic change. But the other 2 were delayed in diagnosis and showed worse outcomes. One case who delayed in diagnosis showed a normal value of DBI and Power's ratio. In all patients, initial cervical lateral radiography showed prevertebral soft tissue swelling at C2 level. Prevertebral soft tissue swelling at the site of $\mathrm{C} 2$ within the $4 \mathrm{~mm}$ is normal ${ }^{28)}$ In this paper, the initial lateral cervical spine radiography 1case can-not be resolved except for the case in which initial $\mathrm{x}$-ray showed the swelling from the prevertebral soft tissue. But it should not be confirmed that the initial photo 1case soft tissue swelling in the MRI findings in patients was observed. Penning et $\mathrm{al}^{28)}$. according to research results, odontoid fracture in patients with the extent of swelling at the site of C2 indicated 1-8 mm (mean $4.2 \mathrm{~mm}$ ) and Hangman fracture in a patient with $2-11 \mathrm{~mm}$ (mean $6.5 \mathrm{~mm}$ ) respectively. Hyperextension sprain occurred in patients by $11-15 \mathrm{~mm}$ (mean $12.67 \mathrm{~mm}$ ), respectively. Herr et $\mathrm{al}^{20)}$. study, while C1-2 fracture at $1-22 \mathrm{~mm}$ (mean $6.22 \mathrm{~mm}$ ) showed edema. In this study, a mean thickness of soft tissue in patients with AOD to 17.88 (15.18 to 20.17) and other damage from previous studies in patients with more severe edema are shown. 2 cases show normal DBI and 3 show normal Power's ratio. Strong forcing by upper cervical spine injury is suspected in patients with Power's ratio and whose DBI is normal. Even though neurological disorders are invisible, lateral X-ray film in the $\mathrm{C} 2$ level of the prevertebral soft tissue swelling may appear, and therefore, AOD should be checked. We recommend 3D CT or MRI to confirm AOD in these patients. 


\section{CONCLUSION}

AOD is not common injury, but it cause a fatal or potentially devastating outcome. Sometimes diagnosis may be delayed, in part due the lack of clinical or radiological evidence, in part due to the combined injuries such as brain stem and lesions to the vascular structures of the neck. Recently, improved prehospital management and decreased transportation time led to a high more chance to reach AOD patients with survival. So, neurosurgeons increase awareness of the AOD for patients who encounter multiple traumas and show prevertebral soft tissue swelling. Early immobilization of cervical spine, and subsequently occipito-cervical fusion can lead to improved outcomes of patients.

\section{REFERENCES}

1. Adams VI: Neck injuries: I. Occipitoatlantal dislocation - A pathologic study of twelve traffic fatalities. J Forensic Sci 37: 556-564, 1992

2. Ahuja A, Glasauer FE, Alker GJ Jr, Klein DM: Radiology in survivors of traumatic atlanto-occipital dislocation. Surg Neurol 41:112-118, 1994

3. Alker GJ Jr, Oh YS, Leslie EV: High cervical spine and craniocervical junction injuries in fatal traffic accidents: a radiological study. Orthop Clin North Am 9:1003-1010, 1978

4. Anderson AJ, Towns GM, Chiverton N: Traumatic occipitocervical disruption: a new technique for stabilisation. Case report and literature review. J Bone Joint Surg Br 88(11):14641468, 2006

5. Anderson PA, Montesano PX: Morphology and treatment of occipital condyle fractures. Spine 13(7):731-736, 1988

6. Bools JC, Rose BS: Traumatic atlantooccipital dislocation: two cases with survival. AJNR Am J Neuroradiol 7(5):901-904, 1986

7. Brooks AL, Jenkins EB: Atlanto-axial arthrodesis by the wedge compression method. J Bone Joint Surg Am 60(3):279-284, 1978

8. Bucholz RW, Burkhead WZ: The pathological anatomy of fatal atlanto-occipital dislocations. J Bone Joint Surg Am 61(2):248250, 1979

9. Chaljub G, Singh H, Gunito FC, Jr., Crow WN: Traumatic atlanto-occipital dislocation: MRI and CT. Neuroradiology 43 (1):41-44, 2001

10. Dickman CA, Papadopoulos SM, Sonntag VKH, Spetzler RF, Rekate HL, Drabier J: Traumatic occipitoatlantal dislocation. J Spinal Disord 6:300-313, 1993

11. Dickman CA, Sonntag VK, Papadopoulos SM, Hadley MN: The interspinous method of posterior atlantoaxial arthrodesis. J Neurosurg 74(2):190-198, 1991

12. Ferrera PC, Bartfield JM: Traumatic atlanto-occipital dislocation: a potentially survivable injury. Am J Emerg Med 14: 291-296, 1996

13. Gallie W: Fractures and dislocations of the cervical spine. Am
J Surg 46:495-499, 1939

14. Grob D: Transarticular screw fixation for atlanto-occipital dislocation. Spine 26(6):703-707, 2001

15. Grob D, Dvorak J, Panjabi M, Froehlich M, Hayek J: Posterior occipitocervical fusion. A preliminary report of a new technique. Spine 16(3 Suppl):S17-24, 1991

16. Haher TR, Yeung AW, Caruso SA, Merola AA, Shin T, Zipnick RI, et al: Occipital screw pullout strength. A biomechanical investigation of occipital morphology. Spine 24(1):5-9, 1999

17. Hamai S, Harimaya K, Maeda T, Hosokawa A, Shida J, Iwamoto Y: Traumatic atlanto-occipital dislocation with atlantoaxial subluxation. Spine 31(13):E421-424, 2006

18. Harms J, Melcher RP: Posterior C1-C2 fusion with polyaxial screw and rod fixation. Spine 26(22):2467-2471, 2001

19. Henry MB, Angelastro DB, Gillen JP: Unrecognized traumatic atlanto-occipital dislocation. Am J Emerg Med 16:406-408, 1998

20. Herr CH, Ball PA, Sargent SK, Quinton HB: Sensitivity of prevertebral soft tissue measurement at $\mathrm{C} 3$ for detection of cervical spine fractures and dislocations. Am J Emerg Med 16(4): 346-349, 1998

21. Horn EM, Feiz-Erfan I, Lekovic GP, Dickman CA, Sonntag VK: Theodore N. Survivors of occipitoatlantal dislocation injuries: imaging and clinical correlates. J Neurosurg Spine 6(2): 113-120, 2007

22. Jackson RS, Banit DM, Rhyne AL, Darden BV: Upper cervical spine injuries. J Am Acad Orthop Surg 10(4):271-280, 2002

23. Jung JW, Lee SG, Kim IC, Yoo CJ, Kim WK, Park CW: A survived traumatic atlanto-occipital dislocation. Korea J Spine 4(2):62-66, 2007

24. Labler L, Eid K, Platz A, Trentz O, Kossmann T: Atlanto-occipital dislocation: four case reports of survival in adults and review of the literature. Eur Spine J 13(2):172-180, 2004

25. Menendez JA, Wright NM: Techniques of posterior C1-C2 stabilization. Neurosurgery 60(1 Supp1 1):S103-111, 2007

26. Oda I, Abumi K, Sell LC, Haggerty CJ, Cunningham BW, McAfee PC: Biomechanical evaluation of five different occipitoatlanto-axial fixation techniques. Spine 24(22):2377-2382, 1999

27. Papadopoulos SM, Dickman CA, Sonntag VKH, Rekate HL, Spetzler RF: Traumatic atlantooccipital dislocation with survival. Neurosurgery 28:574-579, 1991

28. Powers B, Miller MD, Kramer RS, Martinez S, Gehweiler JA Jr: Traumatic anterior atlanto-occipital dislocation. Neurosurgery $4(1): 12-17,1979$

29. Penning L: Prevertevbral hematoma in cervical spine injury: incidence and etiologic significance. AJR Am Roentqenol 136: 553-561, 1981

30. Reisner A, O'Brien MS: Atlanto-occipital dislocation. Contemp Neurosurg 14:1-7, 1992

31. Steinmetz MP, Lechner RM, Anderson JS: Atlantooccipital dislocation in children: presentation, diagnosis, and management. Neurosurg Focus 14(2):ecp1, 2003

32. Traynelis VC, Marano GD, Dunker RO, Kaufman HH: Traumatic atlanto-occipital dislocation. Case report. J Neurosurg 65(6):863-870, 1986

33. Zipnick RI, Merola AA, Gorup J, Kunkle K, Shin T, Caruso SA, et al: Occipital morphology. An anatomic guide to internal fixation. Spine 21(15):1719-1724, 1996 